\begin{tabular}{|c|l|}
\hline Title & Fabrication of SPS compacts from NbC-NbB2 powder mixtures synthesized by the MA-SHS in air process \\
\hline Author(s) & Tsuchida, T.; Kakuta, T. \\
\hline Citation & $\begin{array}{l}\text { Journal of A lloys and Compounds, 415(1-2), 156-161 } \\
\text { https://doi.org/10.1016/.jallcom.2005.08.012 }\end{array}$ \\
\hline Issue Date & 2006-05-18 \\
\hline Doc URL & http://hdl.handle.net/2115/13464 \\
\hline Type & article (author version) \\
\hline File Information & B5525.pdf \\
\hline
\end{tabular}

Instructions for use 


\title{
Fabrication of SPS compacts from NbC-NbB 2 powder mixtures synthesized by the MA-SHS in air process
}

\author{
Takeshi Tsuchida* and Tsuyoshi Kakuta
}

Division of Materials Chemistry, Graduate School of Engineering, Hokkaido University, N13 W8, Kita-ku, Sapporo, 060-8628, Japan

\begin{abstract}
When the powder mixture of $\mathrm{Nb} / \mathrm{B} / \mathrm{C}=2 / 2 / 1$ in molar ratio was mechanically activated (MA) by ball milling for $105 \mathrm{~min}$ and then exposed to air, it self-ignited spontaneously and the self-propagating high-temperature synthesis (SHS) was induced. The powder mixture of $\mathrm{NbC}$ and $\mathrm{NbB}_{2}$ was obtained by this MA-SHS in air process and then sintered by spark plasma sintering (SPS) at a temperature as low as $1800^{\circ} \mathrm{C}$. The sintered $\mathrm{NbC} / \mathrm{NbB}_{2}$ composite compact showed the fine, homogeneous microstructure consisting of the a few $\mu \mathrm{m}$-sized grains and the Vickers hardness of $19.8 \mathrm{GPa}$, which was higher than $14.3 \mathrm{GPa}$ and $16.6 \mathrm{GPa}$ for the $\mathrm{NbC} / \mathrm{NbB}_{2}$ composite compacts sintered from the powder mixture of $\mathrm{Nb} / \mathrm{B} / \mathrm{C}=2 / 2 / 1$ without MA-SHS and from the commercial powder mixture of $\mathrm{NbC} / \mathrm{NbB}_{2}=1 / 1$.
\end{abstract}

\section{Keywords:}

Mechanical activation (MA); Self-propagating High-temperature Synthesis (SHS); Spark plasma sintering (SPS); Ball milling; $\mathrm{NbC} / \mathrm{NbB}_{2}$ composite; $\mathrm{Nb} / \mathrm{B} / \mathrm{C}$ powder mixtures; Vickers hardness

*Corresponding author: Takeshi Tsuchida

Tel/Fax: +81 117066578

e-mail address: tsuchida@eng.hokudai.ac.jp 


\section{Introduction}

Carbides and borides of niobium have excellent properties such as high melting temperature, high strength, high thermal and electrical conductivity, and chemical stability. Therefore, the use of these ceramics in composites can be expected to offer potential candidates for a variety of high-temperature structural applications. Actually, the mechanical properties of the composites, such as mechanical strength, hardness and fracture toughness are controlled by densification and microstructure of the sintered bodies. In particular, because it is known that ceramic materials with fine microstructures, especially nanocomposites, exhibit improved mechanical properties [1], the preparation of the fine particles of $\mathrm{NbC}$ and $\mathrm{NbB}_{2}$ and the homogeneous mixing between them are definitely important. We have so far developed a mechanical activation assisted self-propagating high-temperature synthesis (MA-SHS in air process), and successfully applied to the synthesis of carbides and nitrides of $\mathrm{Al}, \mathrm{Zr}$ and $\mathrm{Nb}$ [2-9], and borocarbides of $\mathrm{Al}_{3} \mathrm{BC}$ [10]. This technique is based on SHS induced by self-ignition reaction of disordered carbon when the mechanically activated metal-graphite powder mixtures were exposed to air $[2,4]$. Thus, this process does not need any expensive reaction equipments and is a very simple, energy-saving technique. In the latest studies $[9,11]$, it is expected that the fine powder mixtures of $\mathrm{ZrC}-\mathrm{ZrB}_{2}$ and $\mathrm{NbC}-\mathrm{NbB}_{2}$ synthesized by the MA-SHS in air process from the powder mixtures of $\mathrm{Zr} / \mathrm{B} / \mathrm{C}$ and $\mathrm{Nb} / \mathrm{B} / \mathrm{C}$ are a promising candidate as precursor of the $\mathrm{ZrC} / \mathrm{ZrB}$ and $\mathrm{NbC} / \mathrm{NbB}_{2}$ composites.

On the other hand, there is another problem that the sintering of $\mathrm{NbC}$ and $\mathrm{NbB}_{2}$ powders to form the composite is a difficult process because of the high melting point and high vapor pressure of the constituents. Spark plasma sintering (SPS) is one of the most powerful candidates to densify poorly sinterable materials such as $\mathrm{NbC}$ and $\mathrm{NbB}_{2}$. SPS is a noble sintering process that allows compaction of ceramic powders at very lower temperature with shorter holding time than in more conventional sintering process, and then depresses grain growth. The sample is loaded in a graphite die, uniaxial pressure is applied during the sintering by the top and bottom punches, and a pulsed direct current is allowed to pass through the die and the sample. The pulses generate spark discharge and/or plasma between powder particles. Because the die acts also as a heating source, the sample is effectively heated from both outside and inside. Although the mechanism for densification and grain growth in the SPS process have not been well elucidated yet, Tokita [12] pointed out that the generated spark discharge and/or plasma cleans the surfaces from adsorbed species, such as 
$\mathrm{CO}_{2}, \mathrm{H}_{2} \mathrm{O}, \mathrm{OH}^{-}$, so that enhances the grain-boundary diffusion process for densification. A systematic study of various spark plasma sintering (SPS) parameters such as temperature, holding time, heating rate, pressure, and pulse sequence was conducted by Shen et al. [13] in order to investigate their effect on the densification, grain-growth kinetics, hardness, and fracture toughness of a commercially available submicrometer-sized $\mathrm{Al}_{2} \mathrm{O}_{3}$ powder.

In the present study, the powder mixture of $\mathrm{NbC}$ and $\mathrm{NbB}_{2}$ synthesized by the MA-SHS in air process from the powder mixture of $\mathrm{Nb} / \mathrm{B} / \mathrm{C}=2 / 2 / 1$ was sintered by SPS to obtain the $\mathrm{NbC} / \mathrm{NbB}_{2}$ composite compact. Then, the Vickers hardness was compared with those of the $\mathrm{NbC} / \mathrm{NbB}_{2}$ composite compacts obtained from the powder mixture of $\mathrm{Nb} / \mathrm{B} / \mathrm{C}=2 / 2 / 1$ without MA-SHS and the commercial powder mixture of $\mathrm{NbC} \mathrm{NbB}_{2}=1 / 1$, and discussed on the basis of the microstructures of the sintered bodies.

\section{Experimental procedures}

The powders of niobium metal (particle size of $50 \sim 130 \mu \mathrm{m}, 98 \%$ purity, Kojundo Chemical Laboratory), amorphous boron (practical grade, Sigma Chemical Company) and natural graphite (mean flake size $5 \mu \mathrm{m}, 97 \%$ carbon, $2 \%$ ash and $1 \%$ volatile component, Nippon Kokuen Industry) were used as starting materials. The powders were mixed in a molar ratio of $\mathrm{Nb} / \mathrm{B} / \mathrm{C}=2 / 2 / 1$ in an agate mortar, loaded in a p-7 planetary ball mill (Fritsch, Idar-Oberstein, Germany) in air and then ground. The mixing ratio was supposed to be a corresponding ratio of $\mathrm{NbC} / \mathrm{NbB}_{2}=1 / 1$ as the product phases. After grinding for $105 \mathrm{~min}$, the ground sample was transferred into a graphite crucible and exposed to air. Just then, it self-ignited and the exothermic reactions propagated into the reactant powders. As soon as the reactions started, the graphite crucible was covered with another one to prevent the sample from further oxidizing. The particle size and morphology of starting materials, and the detail of the MA-SHS in air process have been previously described [9]. The obtained powder mixtures (which is called MA-SHS sample hereafter) were loaded in a graphite die $(10 \mathrm{~mm}$ in diameter) and spark plasma sintered at $1600-1800^{\circ} \mathrm{C}$ for $10-30$ min under a vacuum of $6-10$ $\mathrm{Pa}$ with SPS apparatus (SPS-510L, Sumitomo Coal Mining Co., Tokyo, Japan). The temperature was measured with an optical pyrometer focused on the surface of the graphite die and automatically heated from room temperature to $600^{\circ} \mathrm{C}$ at heating rate of $120^{\circ} \mathrm{C} \mathrm{min}-1$ and then up to $1800^{\circ} \mathrm{C}$ at $60^{\circ} \mathrm{C} \mathrm{min}^{-1}$. A pressure of $40 \mathrm{MPa}$ and an on-off pulse sequence of 
12:2 were applied to the sample during entire sintering time. At the end of the holding time, the pressure was released and the current was shut off. For the comparison, the following samples were also sintered by SPS: the powder mixture of $\mathrm{Nb} / \mathrm{B} / \mathrm{C}=2 / 2 / 1$ which was merely mixed in an agate mortar without mechanical activation (which is called the mixing sample); the powder mixture of $\mathrm{NbC} / \mathrm{NbB}_{2}=1 / 1$ which was obtained by mixing the commercially available samples in an agate mortar (which is called the commercial sample). The purity of the commercial $\mathrm{NbC}$ and $\mathrm{NbB}_{2}$ powders was $99 \%$ (Kojundo Chemical Laboratory) and their particle size was estimated to be $<2 \mu \mathrm{m}$ from SEM microphotographs shown in Fig.1.

The density of the sintered samples was measured by Archimedes method. Before X-ray diffraction (XRD), scanning electron microscopy (SEM) and the Vickers hardness (HV) measurements, the surface of the sintered samples was mirror-like polished with $1.0 \mu \mathrm{m}$ diamond slurries. The crystalline phases were identified by XRD (RINT-2000, Rigaku Denki) using Ni-filtered $\mathrm{CuK} \alpha$ radiation $(30 \mathrm{kV}, 15 \mathrm{~mA})$. The microstructures were observed on the polished surfaces and the fracture surfaces with scanning electron microscopy (JSM-5410-SEM-EPMA-WDX combined microanalyzer, JEOL). For the SEM observation, the powder sample was dispersed in ethanol by ultrasonication, and was placed as a drop on a glass plate or a brass stub and then dried. The Vickers hardness at room temperature was evaluated by Vickers indentation technique at a load of 4.9 MPa. More than five indents were made at the middle of each sample.

\section{Results and discussion}

The reaction mechanism of the MA-SHS in air process for the formation of $\mathrm{NbC}$ and $\mathrm{NbB}_{2}$ from the powder mixture of $\mathrm{Nb} / \mathrm{B} / \mathrm{C}=2 / 2 / 1$ has been already discussed in the previous paper [9]. In the MA-SHS in air process, it was found to be essential that graphite is converted into finely divided, disordered carbon by mechanical activation and mixed with the particles of $\mathrm{Nb}$ and $\mathrm{B}$ in an intimate contact state.

Fig. 2 shows the XRD patterns of powder mixture of $\mathrm{Nb} / \mathrm{B} / \mathrm{C}=2 / 2 / 1$ ground for various times. The disappearance of the graphite peaks, and the decreasing in intensity and broadening of the $\mathrm{Nb}$ peaks with increasing grinding time indicate the formation of disordered carbon, and the size reduction and the increase in the lattice strain in $\mathrm{Nb}$ particles. After the grinding of $105 \mathrm{~min}$, the powder mixture self-ignited in air and the subsequent exothermic 
reactions violently occurred evolving white heat. The evolution of the formation enthalpies of $\mathrm{NbC}$ and $\mathrm{NbB}_{2}$, i.e., $-140 \mathrm{~kJ} \mathrm{~mol}^{-1}$ and $-250 \mathrm{~kJ} \mathrm{~mol}^{-1}$ in the temperature range of $300-1500^{\circ} \mathrm{C}$, sustained completely the SHS process. After the reaction, as shown in Fig.2, $\mathrm{NbC}$ and $\mathrm{NbB}_{2}$ were detected as product phases. In addition, a very small amount of $\mathrm{Nb}$ metal remained unreacted, suggesting that a small part of amorphous boron and disordered carbon remained unreacted as well. From the secondary electron image (SEI) and associated elemental maps of the MA-SHS product shown in Fig.3, it was found that the particles of $\mathrm{NbC}$ and $\mathrm{NbB}_{2}$ obtained by the MA-SHS in air process are a few $\mu \mathrm{m}$-sized grains and homogeneously mixed each other, therefore they are expected to be a promising candidate as precursor of the $\mathrm{NbC} / \mathrm{NbB}_{2}$ composites.

Fig.4 and Fig.5 show the XRD patterns and the SEM microphotographs of the $\mathrm{NbC} / \mathrm{NbB}_{2}$ composite compacts sintered by SPS at $1800^{\circ} \mathrm{C}$ for 10 min under a vacuum of 6-10 $\mathrm{Pa}$ from three samples, (i) the MA-SHS sample, (ii) the mixing sample and (iii) the commercial sample. As can be seen from the XRD results, the peaks of $\mathrm{NbC}$ and $\mathrm{NbB}_{2}$ obtained from the samples (ii) and (iii) were detected in the almost same intensity (Fig.4c, d), whereas the phases obtained from the sample (i) was identified in a following order of intensity, $\mathrm{NbC}>\mathrm{NbB}_{2}>>\mathrm{Nb}_{3} \mathrm{~B}_{4}>\mathrm{Nb}$ (Fig.4b). From a decrease in intensity of unreacted $\mathrm{Nb}$ peaks after SPS runs, it is estimated that the following reactions among unreacted $\mathrm{Nb}, \mathrm{C}$ and $\mathrm{B}$ elements were carried out, $\mathrm{Nb}+\mathrm{C} \rightarrow \mathrm{NbC}$ and $\mathrm{Nb}+\mathrm{B} \rightarrow \mathrm{Nb}_{3} \mathrm{~B}_{4}$. Furthermore, according to EPMA observation, the light phase and the grey phase in Fig.5 are $\mathrm{NbC}$ and $\mathrm{NbB}_{2}$, respectively. Among these composite compacts, the very fine, homogeneous microstructure can be observed in the MA-SHS and commercial sample compacts in Figs.5(a) and (c), and a lot of pores of $\sim 1 \mu \mathrm{m}$ are also seen in the former compact. The grain size of $\mathrm{NbC}$ and $\mathrm{NbB}_{2}$ is $<5 \mu \mathrm{m}$ and is nearly equivalent to the particle size of the samples before sintering as shown in Figs.1 and 3, indicating retardation of grain growth during SPS process. In contrast, the compact from the mixing sample of $\mathrm{Nb} / \mathrm{B} / \mathrm{C}=2 / 2 / 1$ in Fig.5(b) showed the relatively heterogeneous microstructure containing the grain $>10 \mu \mathrm{m}$. The relative density and the Vickers hardness, HV of these compacts are summarized in Table 1: $91.0 \%$ and 13.3 GPa for the MA-SHS sample compact; $96.7 \%$ and $14.3 \mathrm{GPa}$ for the mixing sample compact; $97.7 \%$ and 16.6 GPa for the commercial sample compact. Apparently, the lowest value of relative density and $\mathrm{HV}$ for the MA-SHS sample compact seems to be attributable to its porous structure shown in Fig.5(a). Therefore, the elimination of pores from the MA-SHS 
sample compact having a fine grain-sized, homogeneous microstructure can be expected to improve the mechanical property such as Vickers hardness. Then, the effect of the unreacted $\mathrm{C}$ and $\mathrm{B}$ elements that remained in the MA-SHS sample on the pore formation was investigated.

Fig.6 shows the SEM microphotographs of the SPS compacts obtained from the commercial sample which the $\mathrm{C}$ or $\mathrm{B}$ element was added to in a molar ratio of $\mathrm{NbC} / \mathrm{NbB}_{2} / \mathrm{C}$ (or $\mathrm{B})=45 / 45 / 10$. The XRD patterns of these compacts showed only the $\mathrm{NbC}$ and $\mathrm{NbB}_{2}$ phases. Compared with the SEM microphotographs shown in Fig.5(c), it was found that the addition of $\mathrm{C}$ and $\mathrm{B}$ elements to the commercial $\mathrm{NbC} / \mathrm{NbB}_{2}$ sample led to an increase in the pore size, particularly the C-added sample showed the development of about $10 \mu \mathrm{m}$-sized pore. Such pore formation may be considered to have resulted from the oxidation and vaporization of the $\mathrm{C}$ and B elements although the SPS runs were carried out under vacuum. The values of relative density and Vickers hardness of these compacts were decreased by the formation of porous microstructure as shown in Table 1: $94.9 \%$ and $14.5 \mathrm{GPa}$ for the sample of $\mathrm{NbC} / \mathrm{NbB}_{2} / \mathrm{C}=45 / 45 / 10 ; 95.6 \%$ and $15.3 \mathrm{GPa}$ for the sample of $\mathrm{NbC} / \mathrm{NbB}_{2} / \mathrm{B}=45 / 45 / 10$.

Then, we have tried to separate and remove the unreacted C (density, $\mathrm{d}=2.25$ ) and $\mathrm{B}$ $(d=2.34)$ elements from the MA-SHS sample $\left(d=8.56\right.$ for $\mathrm{Nb}, 7.80$ for $\mathrm{NbC}, 6.93$ for $\left.\mathrm{NbB}_{2}\right)$ by heavy liquid separation using tetrabromoethan $(d=2.96)$. The sample of several grams was taken into a separatory funnel with tetrabromoethan of $100 \mathrm{ml}$ and shaken for enough time and allowed to stand for three days. Then, only the sample settled in the bottom was separated, washed with acetone and dried. Such MA-SHS sample separated from the C and B elements was compacted by SPS at the same sintering conditions. The phases of the obtained compact were identified by XRD in the following order of intensity, $\mathrm{NbC}>>\mathrm{NbB}_{2}=\mathrm{Nb}_{3} \mathrm{~B}_{4}>\mathrm{Nb}$. In contrast to the increase in intensity of $\mathrm{NbC}$ peaks, the decrease in intensity of $\mathrm{NbB}_{2}$ peaks and the increase in intensity of $\mathrm{Nb}_{3} \mathrm{~B}_{4}$ peaks probably indicate the progress of the reaction, $\mathrm{NbB}_{2}+$ $\mathrm{Nb} \rightarrow \mathrm{Nb}_{3} \mathrm{~B}_{4}$. Fig.7 shows the SEM microphotograph of the compact sintered at $1800^{\circ} \mathrm{C}$. The pores in the sintered compact are remarkably eliminated and the homogeneous microstructure consisting of a few $\mu \mathrm{m}$-sized grains can be observed. And, its Vickers hardness increased to $19.8 \mathrm{GPa}$ as shown in Table 1. Regardless of the low relative density of $94.0 \%$, this value was higher than 16.6 GPa of the commercial sample compact of the relative density of $97.7 \%$. It can be easily considered that the sintering behavior and the densification rate strongly depend on the reactivity of the starting powder, such as particle size, specific surface 
area, surface defect structure and so on. Therefore, the better value of Vickers hardness of the MA-SHS sample compact obtained after elimination of the unreacted C and B elements seems to primarily depend on its smaller grain-sized, homogeneous microstructure. A similar hardness-grain size dependence has been obtained for the MA-SHS sample compact of the $\mathrm{Zr} / \mathrm{B} / \mathrm{C}$ system [14]. In addition, it was found from the SEM observation of the fracture surfaces that many cracks were deflected at the grain boundaries, which would lead the increase in the fracture toughness because of the limited mobility of dislocation in small grains. In order to discuss on the hardness and/or fracture toughness-grain size dependence in detail, the high resolution TEM study about the interface structure of $\mathrm{ZrC} / \mathrm{ZrB}_{2}$ and $\mathrm{NbC} / \mathrm{NbB}_{2}$ and the dislocation behavior would be required.

In conclusion, it was verified that the MA-SHS in air process is a unique and energy-saving technique to synthesize concurrently the fine particles of $\mathrm{NbC}$ and $\mathrm{NbB}_{2}$. The $\mathrm{NbC} / \mathrm{NbB}_{2}$ composite compact was sintered by SPS technique from this sample at a temperature as low as $1800^{\circ} \mathrm{C}$, and showed a fine grain-sized, homogeneous microstructure and Vickers hardness, HV of $19.8 \mathrm{GPa}$, which was higher than 14.3 and $16.6 \mathrm{GPa}$ for the $\mathrm{NbC} / \mathrm{NbB}_{2}$ composite compacts obtained from the powder mixture of $\mathrm{Nb} / \mathrm{B} / \mathrm{C}=2 / 2 / 1$ without MA-SHS and from the commercial powder mixture of $\mathrm{NbC} / \mathrm{NbB}_{2}=1 / 1$. In addition, it would be possible to synthesize the nanocomposite of $\mathrm{NbC}_{\mathrm{NbB}}$, when the MA-SHS sample consisting of nanosized particles would be available as a starting powder.

\section{Acknowledgement}

The authors gratefully acknowledge support for this research by a Grant-in-Aid for Scientific Research (C) (KAKENHI 14550797)) and by Nippon Sheet Glass Foundation for Materials and Engineering, and also the help received from Dr. K. Kurokawa with SPS experiments. 


\section{References}

[1] K.Niihara, J.Ceramic.Soc.Jpn. 99(10), (1991) 974-986.

[2] T.Tsuchida, T.Hasegawa, and M.Inagaki, J.Am.Ceram.Soc. 77(12), (1994) 3227-3231.

[3] T.Tsuchida, T.Kitagawa, and M.Inagaki, Eur.J.Solid State Inorg.Chem. 32 (1995) 629-638.

[4] T.Tsuchida, and T.Hasegawa, Thermochim. Acta. 276 (1996) 123-129.

[5] T.Tsuchida, T.Hasegawa, T.Kitagawa, and M.Inagaki, J.Eur.Ceram.Soc. 17 (1997) 1793-1795.

[6] T.Tsuchida, T.Kitagawa and M.Inagaki, J.Mater.Sci. 32 (1997) 5123-5126.

[7] T.Tsuchida, M.Kawaguchi, K.Kodaira, Solid State Ionics. 101-103 (1997) 149-154.

[8] T.Tsuchida, and Y.Azuma, J.Mater.Chem. 7(11), (1997) 2265-2268.

[9] T.Tsuchida, and T.Kakuta, J.Alloys and Compounds. 398 (2005) 67-73.

[10] T.Tsuchida, and T.Kan, J.Eur.Ceram.Soc. 19 (1999) 1795-1799.

[11] T.Tsuchida, and S.Yamamoto, J.Eur.Ceram.Soc. 24 (2004) 45-51.

[12] M.Tokita, J.Soc.Powder Technol. Jpn. 30 (1993) 790-804.

[13] Z.Shen, M.Johnsson, Z.Zhao, and M.Nygren, J.Am.Ceram.Soc. 85 (2002) 1921-1927.

[14] T.Tsuchida, and S.Yamamoto, submitted for publication in J.Mater.Sci. 


\section{Figure captions}

Fig.1 The SEM microphotographs of the commercial powders of $\mathrm{NbC}$ and $\mathrm{NbB}_{2}$.

Fig.2 The XRD patterns of the sample of $\mathrm{Nb} / \mathrm{B} / \mathrm{C}=2 / 2 / 1$ which were ground for $0-105 \mathrm{~min}$. The weight ratio of sample to balls, $\mathrm{R}$ is $1 / 10$. After grinding of $105 \mathrm{~min}$, the formation of $\mathrm{NbC}$ and $\mathrm{NbB}_{2}$ by the MA-SHS in air process was detected.

Fig.3 The secondary electron image (SEI) and associated elemental maps of the MA-SHS sample obtained by grinding of 105 min in Fig.2.

Fig.4 The XRD patterns of (a) the MA-SHS sample obtained from the powder mixture of $\mathrm{Nb} / \mathrm{B} / \mathrm{C}=2 / 2 / 1$, and the $\mathrm{NbC} / \mathrm{NbB}_{2}$ composite compacts obtained by SPS at $1800^{\circ} \mathrm{C}$ from (b) the MA-SHS sample, (c) the mixing sample of $\mathrm{Nb} / \mathrm{B} / \mathrm{C}=2 / 2 / 1$ without MA-SHS and (d) the commercial sample mixed in a ratio of $\mathrm{NbC} \mathrm{NbB}_{2}=1 / 1$. *: The peak of carbon resulted from carbon paper that was used to wrapped the sample powders in SPS runs.

Fig.5 The SEM microphotographs of the $\mathrm{NbC} / \mathrm{NbB}_{2}$ composite compacts sintered by SPS at $1800^{\circ} \mathrm{C}$ from (a) the MA-SHS sample, (b) the mixing sample and (c) the commercial sample.

Fig.6 The SEM microphotographs of the SPS compacts obtained from the commercial sample which the $\mathrm{C}$ or $\mathrm{B}$ element was added to in a molar ratio of (a) $\mathrm{NbC} / \mathrm{NbB}_{2} / \mathrm{B}=45 / 45 / 10$ and (b) $\mathrm{NbC} / \mathrm{NbB}_{2} / \mathrm{C}=45 / 45 / 10$.

Fig.7 The SEM microphotograph of the $\mathrm{NbC} / \mathrm{NbB}_{2}$ composite compact sintered by SPS at $1800^{\circ} \mathrm{C}$ from the MA-SHS sample which the unreacted C and B elements were separated and removed from by heavy liquid separation using tetrabromoethan. 
Table 1 . The relative density and the Vickers hardness, $\mathrm{HV}$ of the $\mathrm{NbC} / \mathrm{NbB}_{2}$ composite compacts obtained by SPS at $1600-1800^{\circ} \mathrm{C}$ from the MA-SHS sample (O), the mixing sample and the commercial sample without the MA-SHS process $(\times)$, which are described in detail in text.

\begin{tabular}{|c|c|c|c|c|c|}
\hline Samples & MA-SHS & $\begin{array}{c}\text { Sintering } \\
\text { Temp. }\left({ }^{\circ} \mathrm{C}\right)\end{array}$ & $\begin{array}{c}\text { Holding Time } \\
(\mathrm{min})\end{array}$ & $\begin{array}{c}\mathrm{HV} \\
(\mathrm{GPa})\end{array}$ & $\begin{array}{c}\text { Relative } \\
\text { Density (\%) }\end{array}$ \\
\hline & $\times$ & 1600 & 30 & 8.8 & 95.3 \\
& $\times$ & 1800 & 10 & 14.3 & 96.7 \\
$\mathrm{Nb} / \mathrm{B} / \mathrm{C}=2 / 2 / 1$ & $\mathrm{O}$ & 1700 & 10 & 14.1 & 90.2 \\
& $\mathrm{O}^{*}$ & 1800 & 10 & 13.3 & 91.0 \\
& $\mathrm{O}^{*}$ & 1610 & 10 & 15.9 & 94.6 \\
$\mathrm{NbC} / \mathrm{NbB}_{2}=1 / 1$ & $\times$ & 1800 & 10 & 19.8 & 94.0 \\
$\mathrm{NbC} / \mathrm{NbB}_{2} / \mathrm{B}=45 / 45 / 10$ & $\times$ & 1800 & 10 & 16.6 & 97.7 \\
$\mathrm{NbC} / \mathrm{NbB}^{*} / \mathrm{C}=45 / 45 / 10$ & $\times$ & 1800 & 10 & 15.3 & 95.6 \\
& & & & 14.5 & 94.9 \\
\hline
\end{tabular}

*: The MA-SHS samples from which the unreacted C and B elements were removed by heavy liquid separation. 
Fig.1
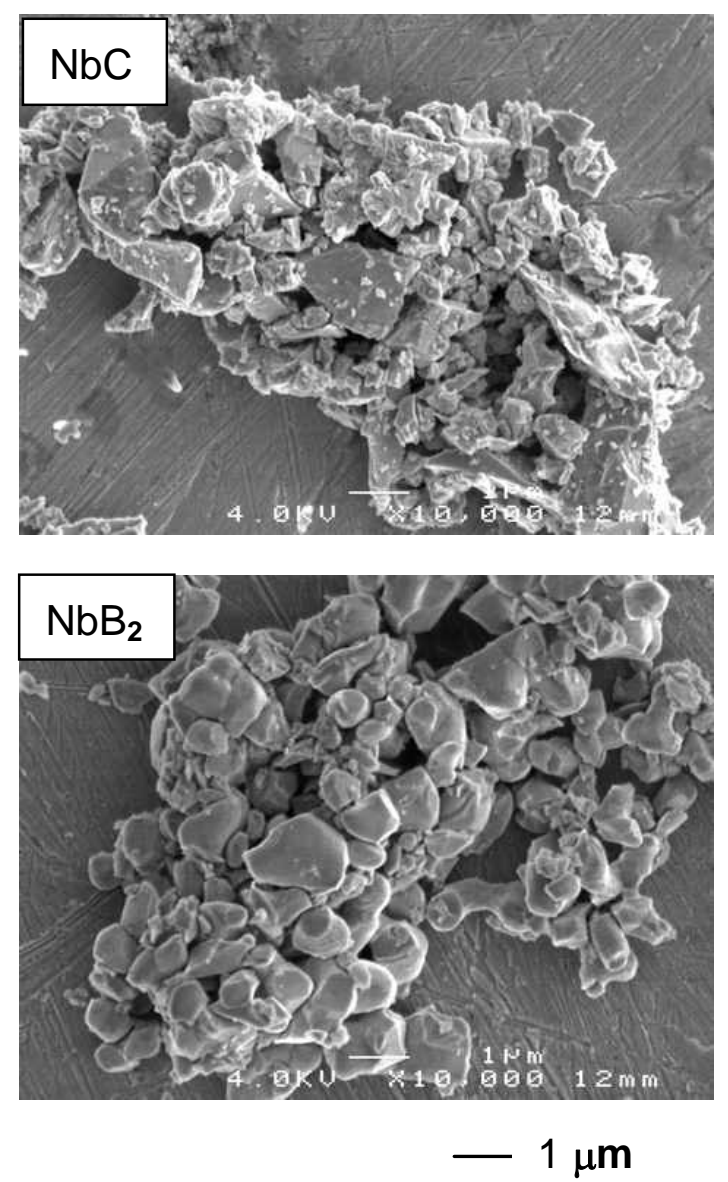
Fig.2

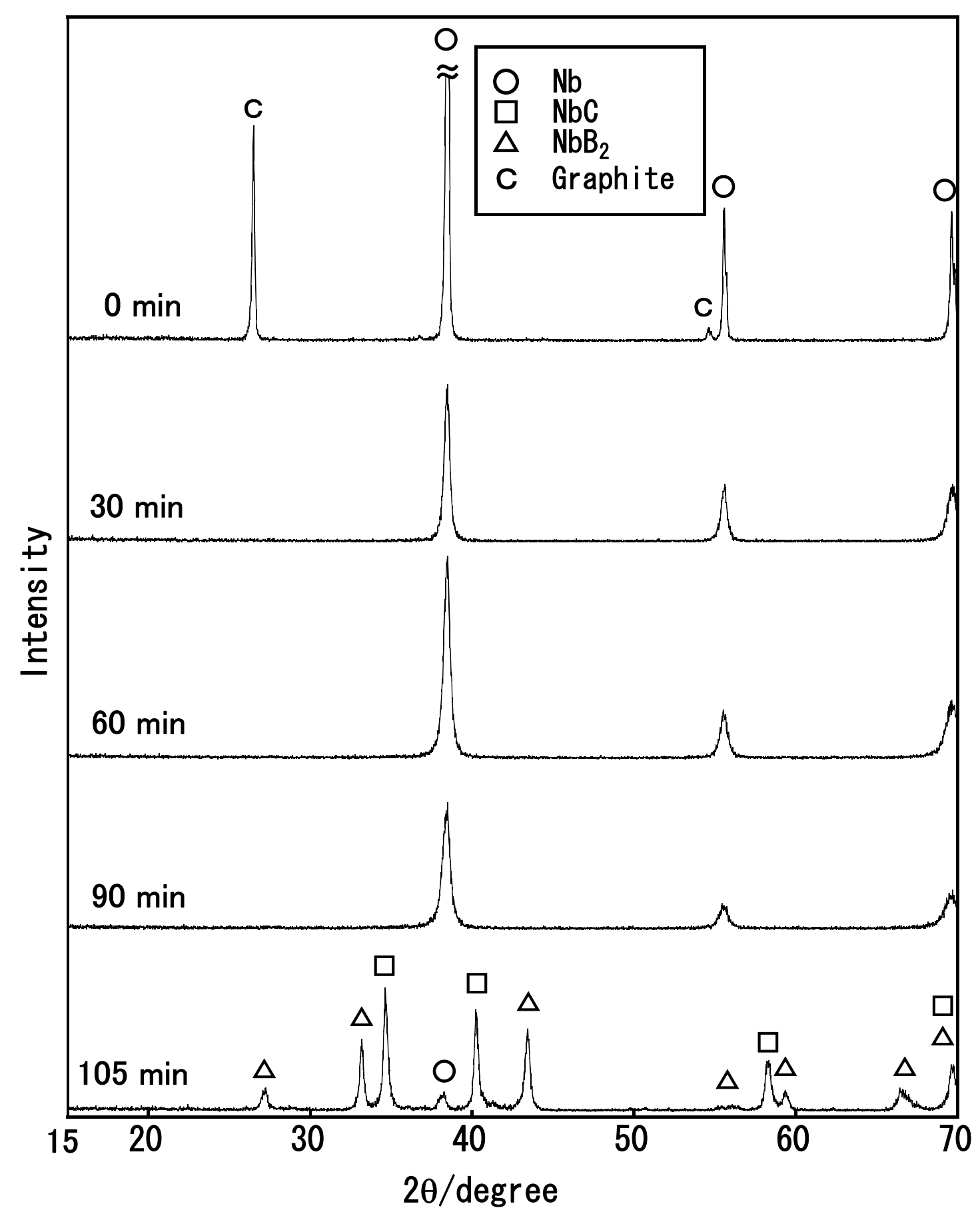


Fig.3
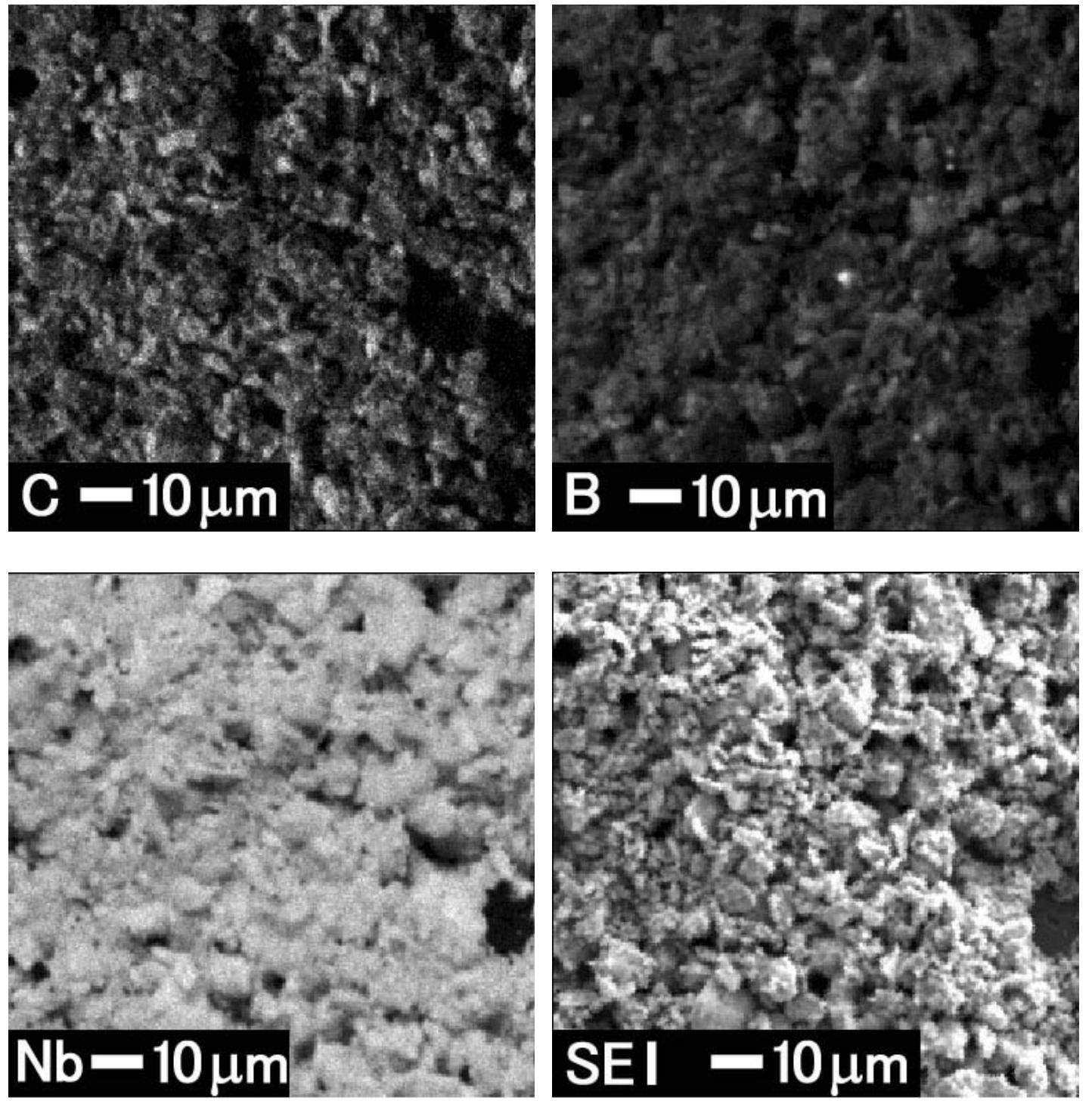
Fig.4

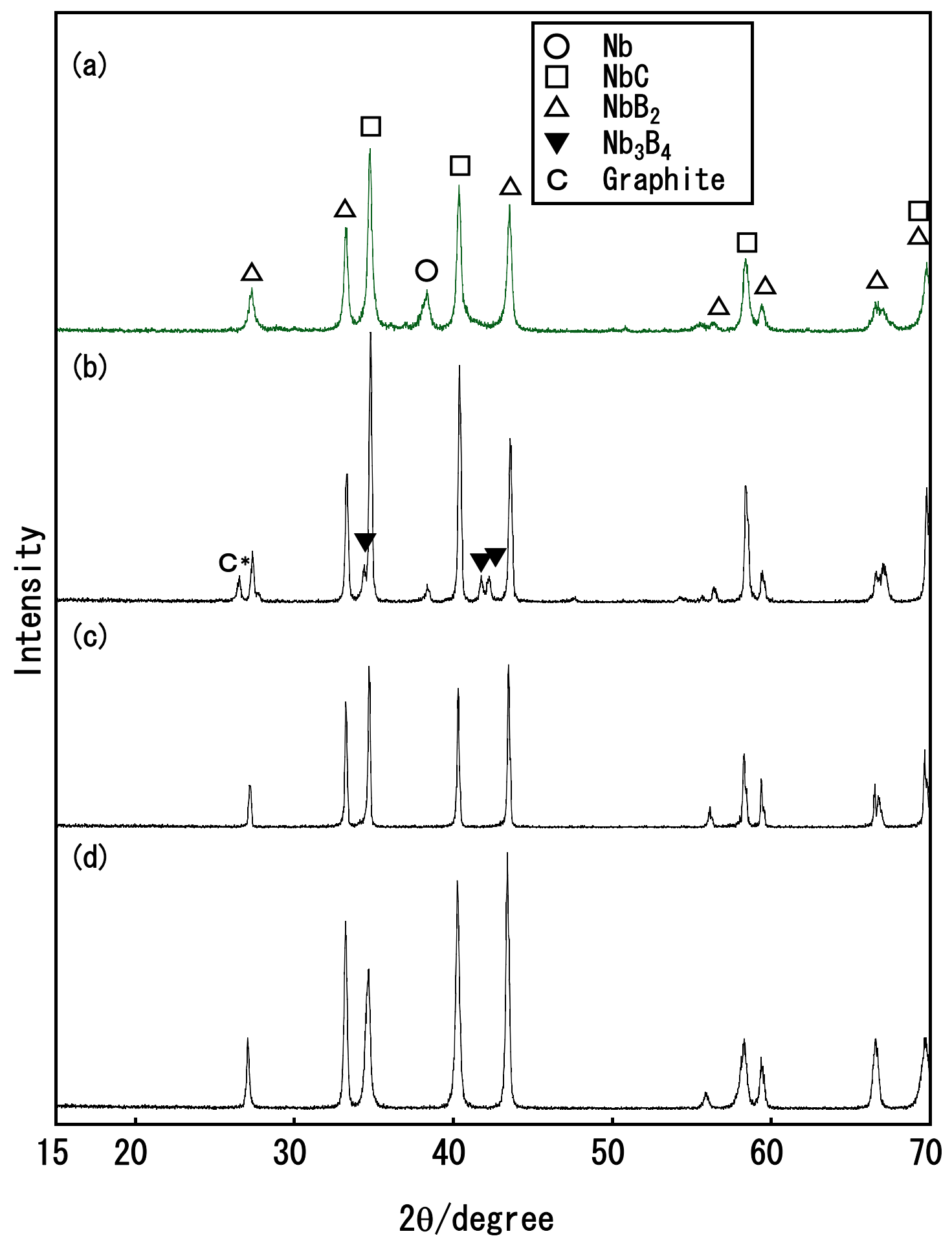


Fig.5
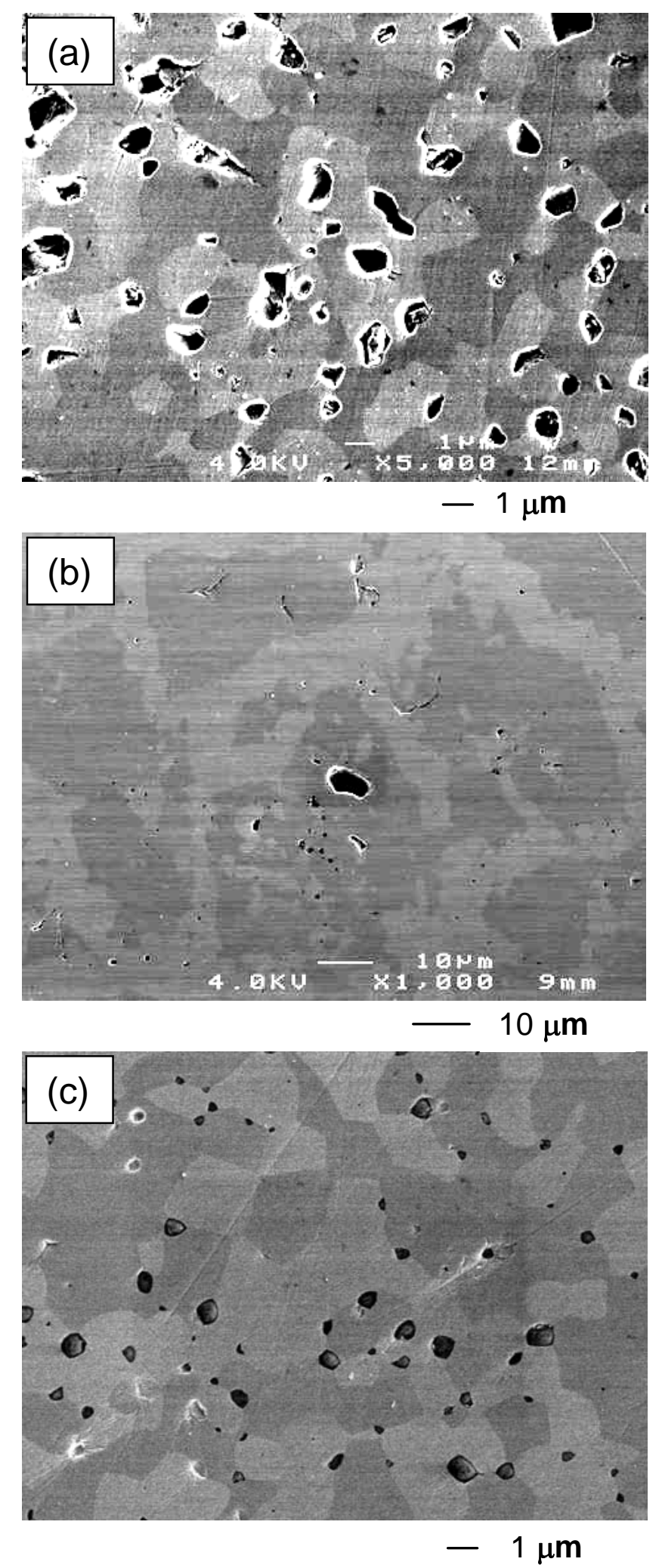
Fig.6
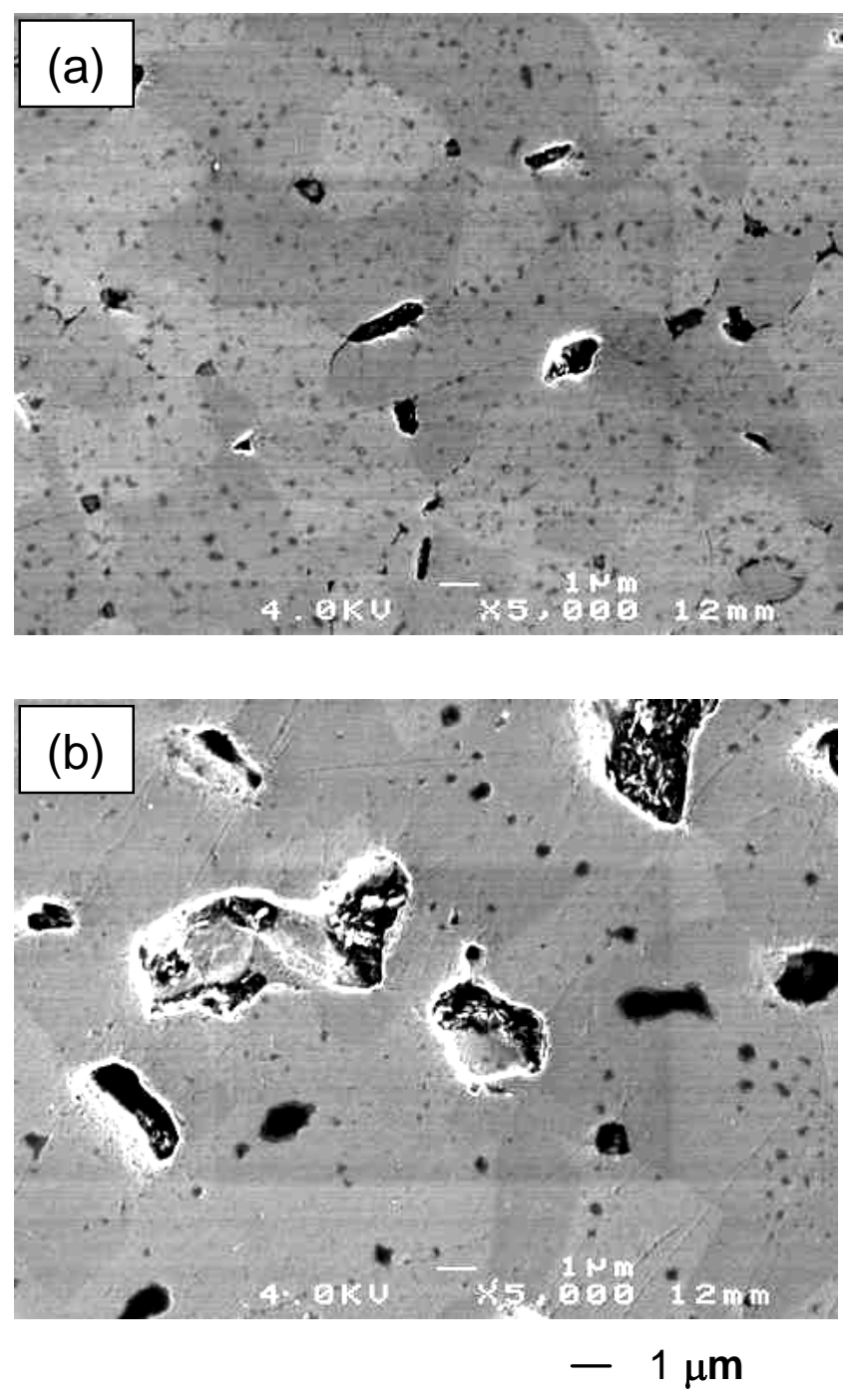
Fig.7

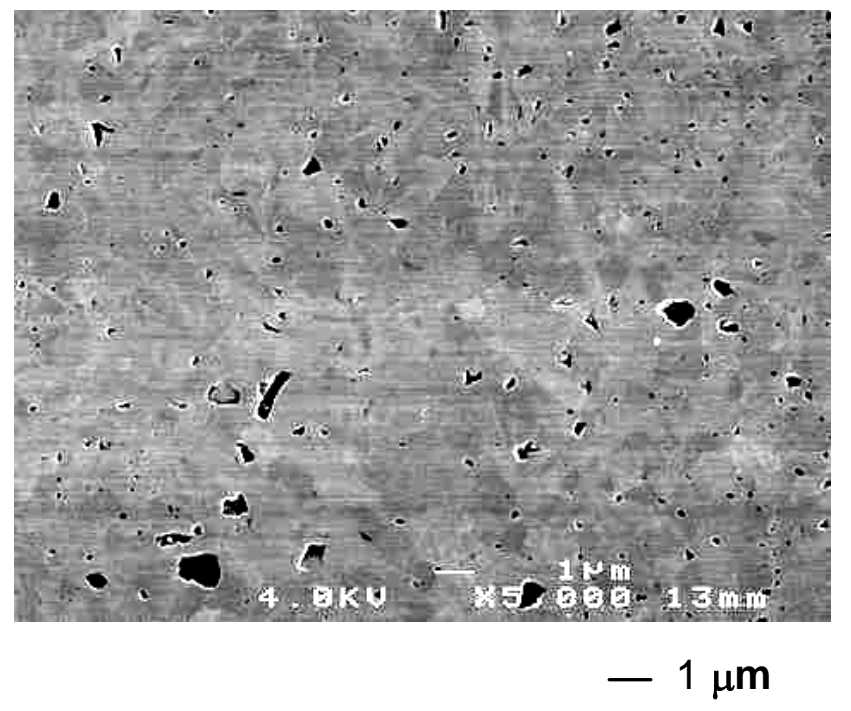

